\title{
Under- and overreporting of energy is related to obesity, lifestyle factors and food group intakes in Jamaican adults
}

\author{
Michelle A Mendez ${ }^{1, *}$, Suzanne Wynter ${ }^{2}$, Rainford Wilks ${ }^{2}$ and Terrence Forrester ${ }^{2}$ \\ ${ }^{1}$ Carolina Population Center, University of North Carolina-Chapel Hill, CB\# 8120, University Square, \\ 123 West Franklin Street, Chapel Hill, NC 27516-2524, USA: ${ }^{2}$ Tropical Medicine Research Institute, \\ University of the West Indies, Kingston, Jamaica
}

Submitted 6 January 2003: Accepted 17 June 2003

\begin{abstract}
Objective: Research in industrialised countries has documented a high prevalence of underreported energy intakes associated with characteristics such as obesity. This paper examines the prevalence, patterns and impact of energy under- and overreporting on diet-obesity relationships in a middle-income developing country. Design: A 70-item food-frequency questionnaire was used. Underreporters had reported energy intakes $<1.35 \times$ basal metabolic rate (BMR), overreporters $>2.4 \times$ BMR. Multinomial models were used to identify characteristics associated with implausible reporting. Intakes were compared across reporting groups to assess evidence of bias. Associations between diet and obesity were compared with and without adjustment for implausible reporting.

Setting: Spanish Town, neighbouring the capital city of Kingston, Jamaica.

Subjects: Eight hundred and ninety-one Jamaican adults, aged 25-75 years, were randomly recruited.

Results: More women than men (38.6\% vs. 22.5\%) underreported, but more men overreported energy (23.7\% vs. $16.0 \%)$. Underreporting was positively associated with obesity, special diets, smoking and age; age was inversely associated with overreporting. Underreporters estimated lower energy from potentially socially undesirable food groups (e.g. snacks) and higher intakes of 'healthy' foods (e.g. fruit) than did plausible reporters. For some of these food groups, significant differences in intakes among normal-weight versus obese subjects observed among plausible reporters were absent when implausible reporters were included. In models of food group-obesity associations, adjusting for implausible energy yielded more credible results that more closely resembled findings in plausible reporters.

Conclusions: Energy under- and overreporting are highly prevalent in Jamaica. Adjusting for implausible reporting may help to reduce bias in diet-health outcome associations.
\end{abstract}

Inaccurate reporting of intakes poses a challenge for research on associations between dietary factors and health outcomes. Using a variety of techniques to identify implausibly low intakes, numerous studies in industrialised countries have documented a high prevalence of underreported energy intakes from 24-hour recalls, food records and food-frequency questionnaires (FFQs) ${ }^{1-5}$. Many of these studies have shown that underreporting is not random, but is related to characteristics such as obesity, smoking, dieting and psychological factors ${ }^{6-10}$. Even more problematic, several studies suggest that underreporters are more likely to estimate low intakes of foods perceived as unhealthy or undesirable than those perceived as healthy ${ }^{4,11}$. Because underreporting is not random, a high prevalence of underreporting may lead to bias in associations between food intake patterns and certain health outcomes. In particular, associations between dietary intakes and obesity or obesity-related health problems may be affected.

Studies in developing countries are increasingly exploring dietary factors that may explain the rising levels of obesity and related chronic diseases. At present, little is known about the prevalence and patterns of dietary misreporting in developing countries, and how inaccurate reporting may influence these analyses. Limited data suggest that the prevalence of underreporting is low in some countries ${ }^{12}$ but not in others ${ }^{13}$. With increasing obesity, underreporting may become more common. Researchers have not yet examined whether patterns and predictors of underreporting in developing countries resemble those observed in the USA and Europe. Moreover, few studies have examined energy 
overreporting. One study in Norway found only 5-7\% overreporting $^{10}$. In countries where undernutrition persists, however, reporting of excessive energy intakes may be more prevalent, particularly if food scarcity is a concern.

The present study in Jamaica uses predicted basal metabolic rate (BMR) to estimate the prevalence of underand overreporting of usual energy intakes. We identify characteristics associated with implausible reporting, and examine food group intake patterns of under- and overreporters, to assess evidence that selected types of foods are systematically over- or underreported. Finally, we examine relationships between food group intakes and overweight/obesity, and evaluate the effect of adjusting for potential reporting bias on these associations.

\section{Data and methods}

Dietary data were collected from 351 men and 539 women residing in and around Spanish Town, Jamaica - a periurban town neighbouring the capital city of Kingston between 1993 and 1995. The study is part of the International Collaborative Study of Hypertension in Blacks $^{14,15}$. A stratified sample of men and non-pregnant women from four age groups (25-34, 35-44, 45-54 and 55-74 years) was recruited from households in enumeration areas selected at random using probability-proportional-to-size. The study was approved by ethics committees at Loyola University Medical Center, Chicago and the University of the West Indies, Mona. Informed consent was obtained from all participants. The response rate was $60 \%$.

Interviewer-administered questionnaires were used to collect self-reported dietary intakes, socio-economic status, demographic characteristics and health status/behaviours. Subjects were asked if they were on any special diet, including diabetic, low-sodium, weight-loss or weight-gain, and vegetarian diets. Trained interviewers collected anthropometric data, including height (to the nearest $0.1 \mathrm{~cm}$ ) and weight (to the nearest $0.1 \mathrm{lb}$ ) measured without shoes and with light clothing. Weight was converted to kilograms by dividing by 2.2046. Body mass index (BMI; weight in $\mathrm{kg}$ divided by the square of height in $\mathrm{m}$ ) was used to classify subjects as overweight $\left(25-29.9 \mathrm{~kg} \mathrm{~m}^{-2}\right)$ and obese $\left(\geq 30 \mathrm{~kg} \mathrm{~m}^{-2}\right.$ ). As the prevalence of obesity in men was low $(6 \%, n=21)$, the categories of overweight and obesity were combined.

\section{Dietary assessment}

A 70-item FFQ designed for Jamaica was used ${ }^{16,17}$. The food list, developed based on 24-hour recall data, included single foods and mixed dishes explaining 90\% of the variance in energy and protein. Trained interviewers asked participants to report usual intakes in the previous
12 months, or when in season for selected foods (mango, avocado, ackee). Local utensils, containers and food models were used as portion size references. Multiple food samples were collected and weighed to quantify portions. Subjects were asked to report consumption in seven frequency categories: almost never, once per month, 2-3 times/month, 2-4 times/week, 5-6 times/week, once per day and $\geq 2$ times/day. Midpoints of each frequency category were multiplied by portion sizes to estimate amounts consumed.

Energy and nutrient content were estimated using published food composition data compiled jointly with Jamaican nutritionists (S.W.) from several sources ${ }^{18-21}$. One subject with reported intake $>54 \mathrm{MJ}$ was excluded. Food items were grouped as follows: (1) cereals/breads; (2) starchy roots/tubers; (3) poultry/meat/eggs; (4) fish (often prepared with high added fat); (5) beans; (6) nuts; (7) vegetables; (8) fruits; (9) fruit juices/drinks; (10) milk/cheese; (11) sweetened dairy products; (12) snacks (including desserts); (13) sugar in tea; (14) table fats; (15) sodas/coffee/tea etc. (including cocoa and sugared drinks); and (16) alcohol.

\section{Under- and overreporting of energy intake}

Schofield equations were used to estimate BMR based on age, weight and $\operatorname{sex}^{22,23}$. The ratio of reported energy intake (EI) to BMR was used to estimate the prevalence of under- and overreporting. A cut-off point of EI $<1.35 \times$ BMR, estimated based on sedentary subjects in calorimeters, was used to identify implausibly low energy intakes, as in other studies ${ }^{10,22,24,25}$. As elsewhere, overreporting was defined as EI $>2.4 \times$ BMR, estimated as the maximum for a very active lifestyle that is sustainable over extended periods ${ }^{10,26}$. Components of the analysis were repeated using an alternative cut-off point of EI $<1.2 \times$ BMR to define underreporting; results were similar (not shown).

\section{Data analysis}

\section{Characterising under- and overreporters}

We first described the prevalence of under- and overreporting, showing mean reported energy intake and BMR in each reporting group. To validate the method used to identify over- and underreporters, we also calculated predicted energy intakes for each group using an independent equation for estimating total energy requirements ${ }^{27}$. We then identified characteristics associated with misreporting. One-way analysis of variance (continuous variables) or chi-square tests (categorical variables) were used to determine whether bivariate associations were significant $(P<0.05)$. Multinomial models were used to identify factors associated with over- or underreporting after adjustment for all characteristics explored in the bivariate analysis. Results are presented as odds ratios (ORs) with 95\% confidence intervals (CIs). 
Characterising food intakes of under-and overreporters Food group intakes were examined to assess whether implausible reporters appeared to selectively misreport items that might be perceived as more or less socially desirable. Comparisons were made using both absolute (MJ) and relative (\% of energy) intakes of food groups. Since some intake distributions were skewed, Wilcoxon's rank sum test was used to compare mean intakes across reporting groups. We also compared the prevalence of high intakes (defined as greater than the sex-specific medians for each food group) across reporting groups.

Associations between food group intakes and obesity Food group intakes of normal versus overweight/obese subjects were also compared in the sample as a whole and in the plausible subgroup. Dichotomous variables (high intakes) were used to minimise the influence of participants reporting large intakes. Results were similar using means (not shown). Multivariate-adjusted associations between food group intakes and weight status were estimated using logistic (overweight/obesity combined) or multinomial models (overweight or obese vs. normal). Models were adjusted for age, energy intakes, other food group intakes and confounders ( $>15 \%$ change-inestimate; influence on model fit) selected from the following: on a special diet, smoking history, education level, poverty status, season and lifestyle efforts to lower blood pressure (exercise, alcohol reduction, salt reduction or weight loss).

Strategies for accounting for implausible energy reporting were compared in order to assess differences in results obtained using alternative approaches. We compared results from multivariate models that: (1) adjusted for total energy intakes and other food group intakes, as well as confounders; (2) also adjusted for over- and underreporting using dummy variables; and (3) were restricted to the plausible energy reporter subgroup. Analysis was conducted using STATA version 7.0 (College Station, TX, USA). Models using absolute versus relative energy intakes yielded similar patterns of results.

\section{Results}

\section{Prevalence of under- and overreporting}

Only about half of the men and women in the sample reported energy intakes within the limits defined as plausible (Table 1). More than a third of women and nearly a quarter of men reported implausibly low intakes. There was also substantial overreporting, particularly among men.

Differences in mean BMR across reporting groups were generally small, suggesting that the large differences in reported intakes may not be credible (Table 1). Indeed, the mean BMR was higher in women underreporters than in plausible or overreporters. In the plausible subgroups, mean predicted energy intakes closely resembled reported

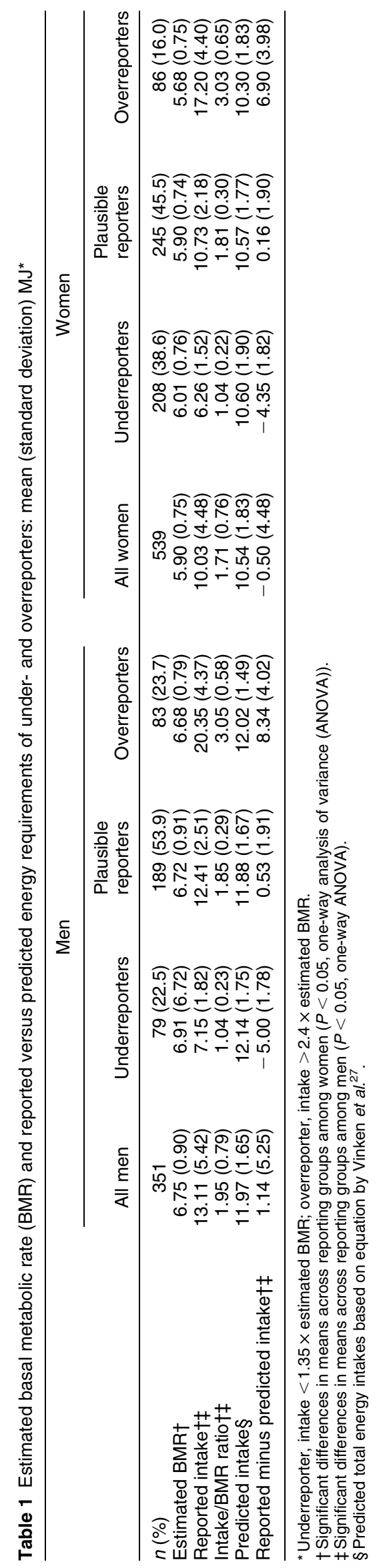


intakes. Among under- and overreporters, however, reported and predicted intakes diverged substantially, suggesting possible bias.

\section{Characteristics of under-and overreporters}

Consistent with our hypotheses, obesity was more prevalent in underreporters and less prevalent in overreporters, than in plausible reporters (Table 2). Among normal, overweight and obese women, the prevalence of underreporting was $25.3 \%, 36.7 \%$ and $57.1 \%$, respectively. Among men, underreporting prevalence was 17.3\%, 34.1\% and $38.1 \%$, respectively, in these groups. Conversely, overreporting in women decreased from $24.7 \%$ in normalweight, to $11.7 \%$ in overweight and $9.9 \%$ in obese subjects. In men, these levels were $26.7 \%, 20.0 \%$ and $4.8 \%$.

Several other factors distinguished underreporters from adults with plausible energy intakes in bivariate analyses. Underreporters were significantly more likely to be on special diets, older and to have more education. They were also less likely to report current smoking. Women interviewed in the summer were also more likely to underreport. Overreporters, on the other hand, were younger and less educated than plausible reporters.

After adjusting for other characteristics postulated as predictors of misreporting, obesity (OR 4.05, 95\% CI 2.366.96), but not overweight (OR 1.58, 95\% CI 0.94-2.65), was significantly associated with underreporting in women. Overweight/obesity was associated with underreporting in men (OR 2.21, 95\% CI 1.17-4.16). Several other factors were significant predictors of underreporting in women. Dieting was associated with underreporting in women (OR 1.79, 95\% CI 1.05-3.06); associations were marginally non-significant in men (OR 2.02, 95\% CI $0.94-$ 4.31). While women $>45$ years old were significantly more likely to underreport (OR 2.48, 95\% CI 1.48-4.15), this was not true for men (OR 1.12, 95\% CI 0.54-2.34). In a multivariate model combining men and women, sex was not significantly associated with over- or underreporting (not shown).

After adjustment, none of the characteristics examined - including weight status - was a significant predictor of overreporting in women. ORs in women were 0.56 (95\% CI 0.30-1.05) for overweight and 0.81 (95\% CI 0.40-1.64) for obesity. Men on special diets were more likely (OR 2.46, 95\% CI 1.11-5.45), and those reporting former alcohol use less likely (OR 0.14, 95\% CI 0.03-0.77), to overreport. However, associations with overweight/obesity were non-significant (OR 0.71, 95\% CI 0.35-1.45).

\section{Food group intakes}

\section{Underreporters}

Expressed as absolute intakes, underreporters estimated significantly lower energy from most food groups than did plausible reporters. Disparities across reporting groups were large, statistically significant $(P<0.05$, Wilcoxon rank sum test) and marked for almost all food groups (not shown). Patterns for relative intakes, however, varied substantially (Fig. 1). Indeed, underreporters estimated

Table 2 Characteristics of over- and underreporters: sociodemographic characteristics, anthropometry and behavioural factors*

\begin{tabular}{|c|c|c|c|c|c|c|c|c|}
\hline & \multicolumn{4}{|c|}{ Men } & \multicolumn{4}{|c|}{ Women } \\
\hline & All men & Underreporters & $\begin{array}{l}\text { Plausible } \\
\text { reporters }\end{array}$ & Overreporters & All women & Underreporters & $\begin{array}{l}\text { Plausible } \\
\text { reporters }\end{array}$ & Overreporters \\
\hline \multicolumn{9}{|c|}{ Sociodemographic characteristics } \\
\hline $\begin{array}{l}\text { Age (years), } \\
\text { mean (SD)†‡ }\end{array}$ & $45.9(14.5)$ & $48.5(14.5)$ & $46.7(14.5)$ & $41.7(13.7)$ & $45.7(13.3)$ & $49.5(12.9)$ & $43.9(13.0)$ & $41.9(12.9)$ \\
\hline $\begin{array}{l}\text { Poor (\%) } \\
\text { Education†‡ }\end{array}$ & 47.0 & 43.2 & 48.0 & 48.6 & 69.9 & 71.1 & 65.9 & 78.2 \\
\hline Any high school (\%) & 26.3 & 14.1 & 25.9 & 38.6 & 22.6 & 15.4 & 26.9 & 27.9 \\
\hline Any college $(\%) \dagger$ & 6.9 & 14.1 & 5.8 & 2.4 & 2.0 & 2.9 & 2.0 & 0.0 \\
\hline \multicolumn{9}{|l|}{ 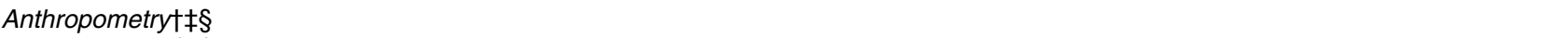 } \\
\hline Normal weight (\%) & 69.6 & 53.2 & 72.7 & 78.3 & 36.7 & 24.0 & 40.4 & 57.0 \\
\hline Overweight (\%) & 24.4 & 36.7 & 20.9 & 20.5 & 33.4 & 31.7 & 38.0 & 24.4 \\
\hline Obese (\%) & 6.0 & 10.1 & 6.4 & 1.2 & 29.9 & 44.2 & 21.6 & 18.6 \\
\hline \multicolumn{9}{|l|}{ Behavioural factors } \\
\hline Any special diet (\%)†‡ & 16.4 & 24.4 & 11.8 & 19.5 & 20.3 & 28.9 & 15.6 & 12.8 \\
\hline Current drinker (\%)‡ & 66.5 & 51.9 & 66.7 & 79.8 & 20.5 & 13.9 & 24.1 & 25.9 \\
\hline \multicolumn{9}{|l|}{ Smoking†‡ } \\
\hline Never (\%) & 38.5 & 50.6 & 33.9 & 37.4 & 81.2 & 84.1 & 80.4 & 76.5 \\
\hline Current (\%) & 39.3 & 27.9 & 42.9 & 42.2 & 11.9 & 7.2 & 13.1 & 20.0 \\
\hline Past $(\%)$ & 22.2 & 21.5 & 23.3 & 20.5 & 6.9 & 8.7 & 6.5 & 3.5 \\
\hline Summer interview (\%)‡ & 57.5 & 58.2 & 59.3 & 53.0 & 55.1 & 60.6 & 54.3 & 44.2 \\
\hline
\end{tabular}

*Definitions: poor - below poverty line, J\$3000 per month; overweight $-\mathrm{BMI}=25-29.9 \mathrm{~kg} \mathrm{~m}^{-2}$; obese $-\mathrm{BMI} \geq 30 \mathrm{~kg} \mathrm{~m}^{-2}$. Forty per cent of the 165 subjects on special diets were on more than one type: 33 diabetic, 9 low-energy, 22 low-fat, 87 low-salt, 22 weight-loss, 7 vegetarian, 1 weight-gain, 51 other.

† Statistically significant differences across reporting groups in men $(P<0.05$, one-way analysis of variance (ANOVA) or chi-square).

$\ddagger$ Statistically significant differences across reporting groups in women $(P<0.05$, one-way ANOVA or chi-square).

$\S$ Percentage of men underweight $\left(\mathrm{BMI}<18.5 \mathrm{~kg} \mathrm{~m}^{-2}\right)$ : overall $-6.0 \%$, underreporters $-3.8 \%$, plausible reporters $-6.4 \%$, overreporters $-7.1 \%$. Percentage of women underweight: overall $-5.8 \%$, underreporters $-4.8 \%$, plausible reporters $-4.1 \%$, overreporters $-12.8 \%$. 

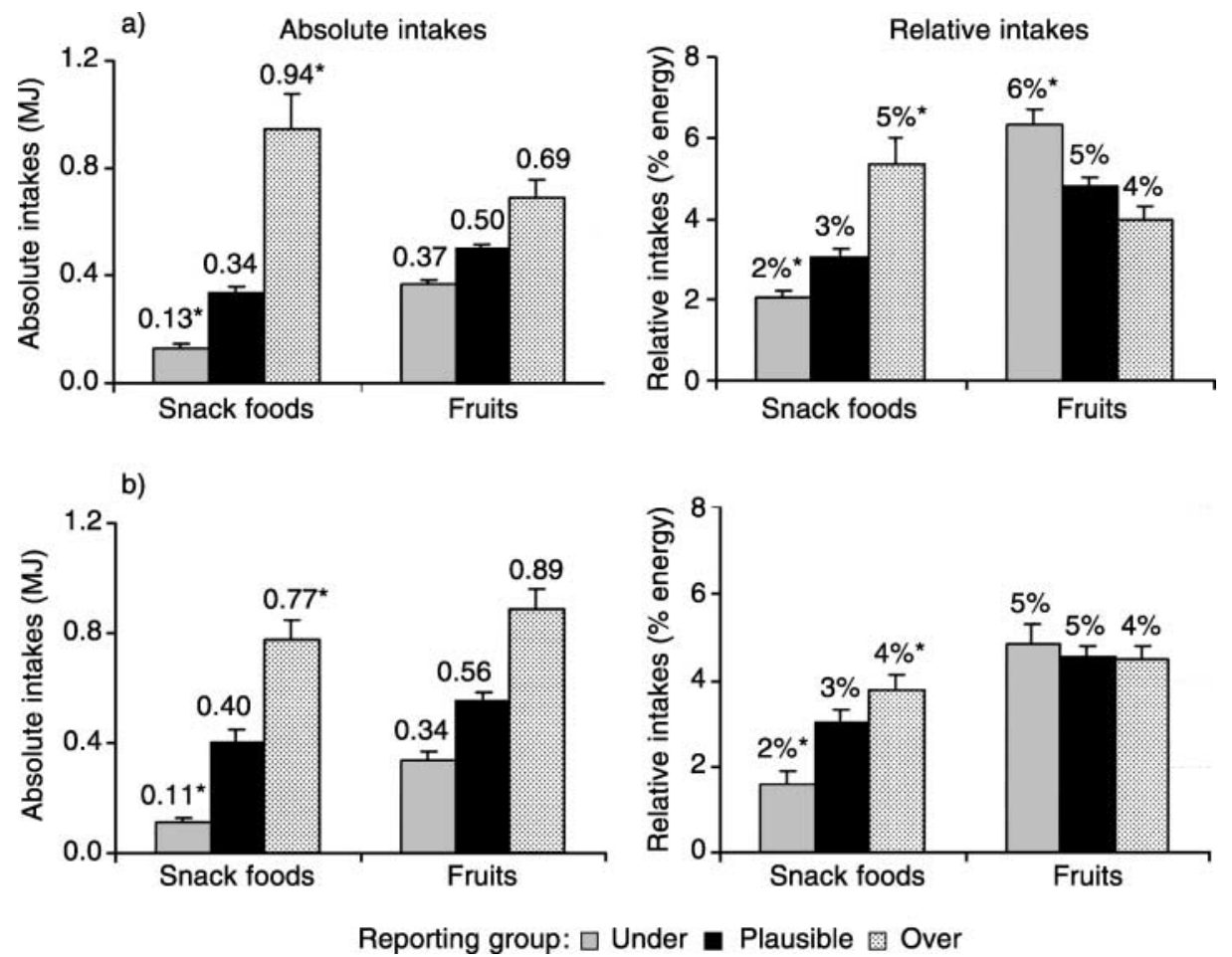

Fig. 1 Mean (bars, standard error) daily intakes of selected food groups for (a) women and (b) men. Absolute intakes were consistently lower in under- and higher in overreporters for all food groups. Relative intakes showed that underreporters estimated lower proportions of energy from potentially less desirable foods (e.g. snacks) and higher proportions from more desirable foods (e.g. fruit). ${ }^{*}, P<0.05$ (Wilcoxon rank sum test)

higher relative intakes from several food groups than did plausible reporters. Using relative rather than absolute intakes, significant differences between under- versus plausible reporters were largely observed among foods potentially influenced by perceptions of healthfulness. Compared with plausible reporters, women underreporters reported significantly lower intakes of several potentially undesirable food groups, namely snack items (2.1 vs. $3.1 \%$ of energy), sweetened dairy products ( $2.3 \mathrm{vs}$. $3.1 \%)$, nuts (1.1 vs. $2.0 \%)$, fruit juices/drinks (1.1 vs. $1.5 \%)$ and alcohol (0.5 vs. 0.8\%) $(P<0.05)$. Conversely, they estimated relatively high intakes of fruits (6.3 vs. $4.7 \%$; $P<0.05)$. Similarly, male underreporters estimated relatively low intakes from snack foods (1.6 vs. 3.0\%), milk/cheese (3.7 vs. 4.7\%), nuts (1.7 vs. $3.5 \%)$ and alcohol (2.4 vs. $4.1 \%)(P<0.05)$. Except for beans $(1.0$ vs. $1.4 \%$ in men under- vs. plausible reporters; 0.9 vs. $1.1 \%$ in women; $P<0.05$ ), there were no significant differences for other food groups.

\section{Overreporters}

Discrepancies in relative intakes of overreporters versus plausible reporters were again concentrated in food groups potentially influenced by social desirability. Women overreporters estimated significantly lower intakes from fruit ( 4.0 vs. $4.8 \%$ ), but higher intakes from table fats (0.56 vs. $0.63 \%)$, nuts (2.1 vs. $3.5 \%)$ and snacks (3.1 vs. $5.3 \%)$, than did plausible reporters $(P<0.05$,
Wilcoxon rank sum test). Among men, overreporters estimated significantly higher intakes of snacks (3.8 vs. $3.0 \%)$ and nuts (6.2 vs. 3.5\%), but lower intakes of roots/tubers (7.4 vs. 8.7\%) and fish (3.0 vs. 3.6\%) than did plausible reporters $(P<0.05)$. Unexpectedly, male overreporters also estimated lower intakes of sugar (1.5 vs. $2.5 \%)$ and sodas/coffee/tea (5.5 vs. 7.3\%) $(P<0.05)$.

\section{Bivariate associations between food group intakes and obesity}

We next compared food group intakes of normal versus overweight/obese subjects in the entire sample with patterns in the sub-sample of plausible reporters. As there were fewer systematic differences with relative as compared with absolute intakes, results are presented only for relative intakes (Fig. 2). Again, discrepancies between the plausible subgroup versus the sample as a whole were concentrated in food groups that may be influenced by social desirability. Among plausible reporters, there were marked disparities in the proportion of normal, overweight and obese women with high intakes of fruit $(51.5,50.5$ and $34.0 \%$, respectively), snacks (43.4, 58.1 and 56.6\%), poultry/meat/eggs (48.5, 47.3 and $64.2 \%)$ and fish $(42.4,55.9$ and $60.4 \%)(P<0.05)$. These disparities were small and non-significant in the sample as a whole: $52.5,51.1$ and $45.3 \%$ for fruit; 48.0, 53.3 and $48.4 \%$ for snacks; 46.0, 50.6 and $54.0 \%$ for poultry/meat/eggs; and 44.4, 50.6 and $55.9 \%$ for fish. 

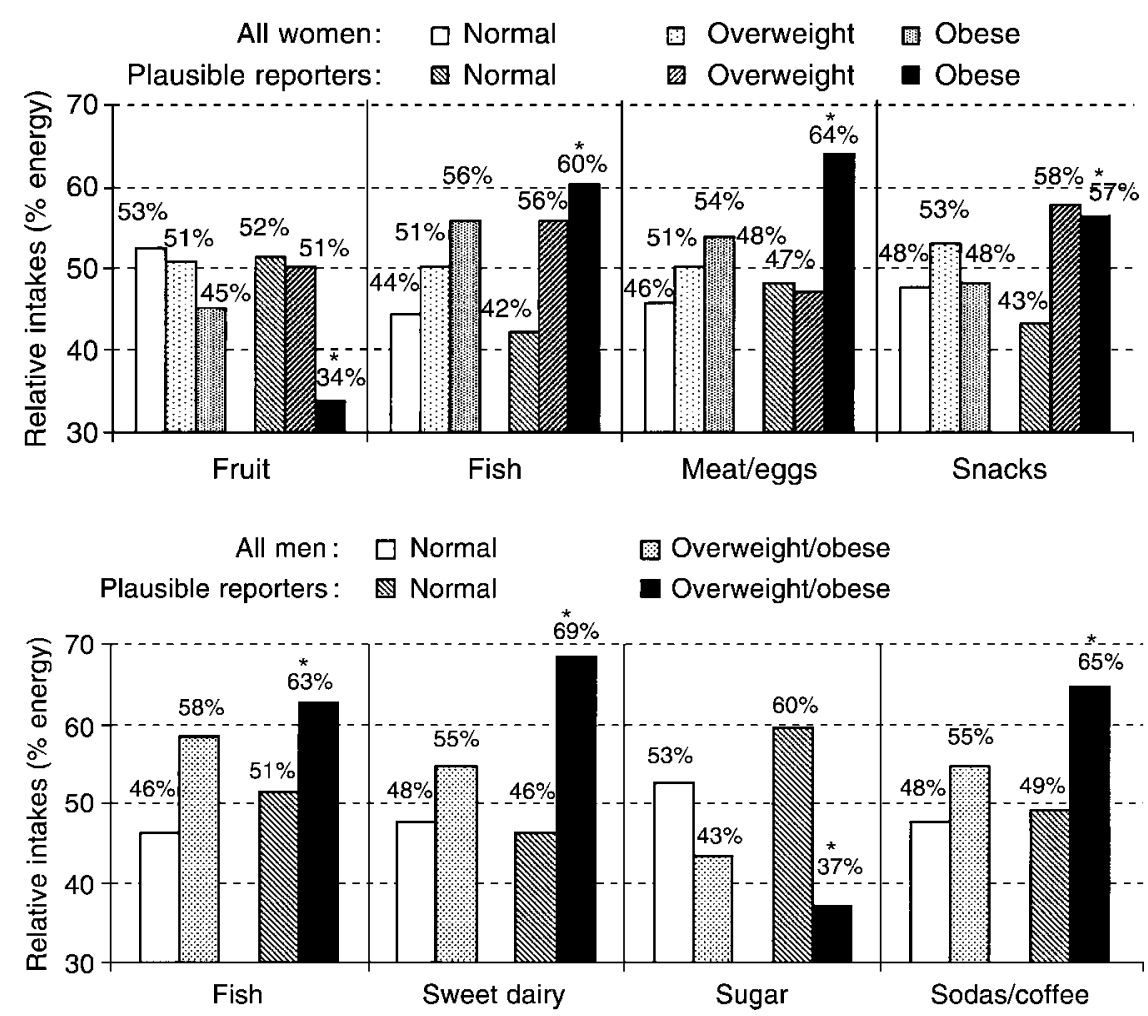

Fig. 2 Reported intakes by weight status in (a) women (all women vs. plausible reporters) and (b) men (all men vs. plausible reporters). For some food groups, disparities in intakes between normal versus overweight and/or obese women were more apparent among plausible reporters than among all women, and disparities in intakes between normal versus overweight/obese men were more apparent among plausible reporters than among all men. ${ }^{\star}, P<0.05$ for differences in intake by weight status (chi-square test)

Similar disparities across samples were observed in men (see Fig. 2b; otherwise not shown). High intakes of sweetened dairy products and sodas/coffee/tea were positively and significantly associated with overweight among plausible reporters, but not in the sample as a whole. More surprisingly, positive associations between overweight and fish intakes were significant only in the sample as a whole and an inverse association between overweight and sugar was present only in plausible reporters. For other food groups, differences across samples in the magnitude or direction of associations were less marked, and there were no disparities in statistical significance.

\section{Multivariate associations between food group intakes and overweight/obesity}

In Tables 3 (women) and 4 (men) we present associations between relative intakes from each food group and weight status. After including dummy variables identifying underand overreporters (model 2), there were significant positive associations between obesity in women and intakes of fish, fruit juices/drinks and snacks. There was a marginally non-significant positive association with poultry/meat/eggs and a significant inverse association with fruit. Compared with model 1, which did not adjust for misreporting, associations were stronger for snacks, fruit juices/drinks and fish (for which disparities between plausible reporters vs. the entire sample were identified earlier), as well as for sodas/coffee/tea. Associations for these food groups were also more similar to those in model 3, in which the analysis sample was limited to plausible reporters. Oddly, high intakes of table fats (butter, margarine) were inversely associated with obesity in women regardless of the model used, suggesting either bias or dietary modification in obese women.

In men, cereals/breads, fish and fruit juices/drinks were positively and significantly associated with being overweight/obese; there was an inverse relationship with beans. Associations with these food groups were generally weaker without adjustment for misreporting, although differences were small. When the sample was restricted to plausible reporters, these associations were strengthened, as were positive associations with sweetened dairy foods, table fats, sodas/coffee/tea and alcohol. Unexpectedly, intakes of vegetables and fruits were positively (albeit non-significantly) associated with overweight in plausible reporters.

Supplementary models were run to examine associations between overweight/obesity and fruit and vegetable consumption more closely, particularly given the positive associations in men with plausible intakes. Among women with plausible energy intakes, there was a non-significant 


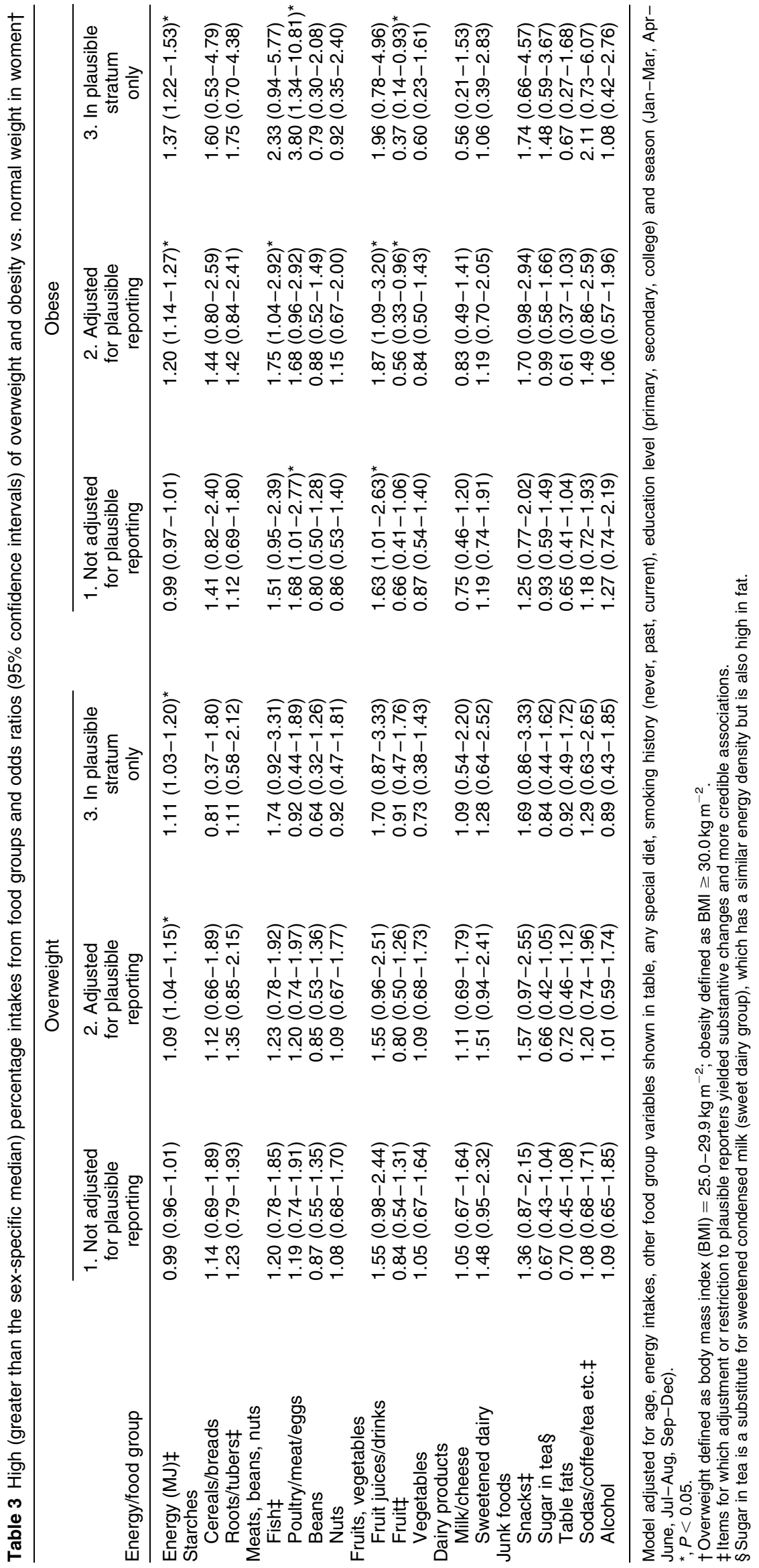


Table 4 High (greater than the sex-specific median) percentage intakes from food groups and odds ratios (95\% confidence intervals) of overweight/obesity versus normal weight in ment

\begin{tabular}{|c|c|c|c|}
\hline Energy/food group & $\begin{array}{l}\text { 1. Not adjusted for } \\
\text { plausible reporting }\end{array}$ & $\begin{array}{l}\text { 2. Adjusted for } \\
\text { plausible reporting }\end{array}$ & $\begin{array}{l}\text { 3. In plausible } \\
\text { stratum only }\end{array}$ \\
\hline Energy (MJ)‡ & $0.99(0.97-1.01)$ & $1.07(1.03-1.12)^{\star}$ & $1.17(1.06-1.29)^{*}$ \\
\hline \multicolumn{4}{|l|}{ Starches } \\
\hline Cereals/breads $\ddagger$ & $1.68(0.94-3.00)$ & $1.72(0.94-3.16)$ & $2.80(1.05-7.46)^{\star}$ \\
\hline Roots/tubers & $0.79(0.44-1.41)$ & $0.70(0.38-1.28)$ & $0.74(0.27-2.01)$ \\
\hline \multicolumn{4}{|l|}{ Meats, beans, nuts } \\
\hline Fish & $2.10(1.21-3.65)^{\star}$ & $2.12(1.18-3.82)^{\star}$ & $2.45(0.96-6.20)$ \\
\hline Poultry/meat/eggs & $1.21(0.69-2.13)$ & $1.13(0.63-2.04)$ & $1.33(0.49-3.60)$ \\
\hline Beansł & $0.59(0.33-1.03)$ & $0.56(0.31-1.00)^{\star}$ & $0.48(0.18-1.24)$ \\
\hline Nuts & $1.44(0.80-2.61)$ & $1.54(0.83-2.87)$ & $0.98(0.39-2.49)$ \\
\hline \multicolumn{4}{|l|}{ Fruits, vegetables } \\
\hline Fruit juices/drinks $\ddagger$ & $2.64(1.47-4.73)^{\star}$ & $3.17(1.69-5.93)^{\star}$ & $3.91(1.34-11.47)^{\star}$ \\
\hline Fruit & $0.91(0.53-1.56)$ & $0.93(0.54-1.63)$ & $1.78(0.72-4.41)$ \\
\hline Vegetables & $1.11(0.64-1.94)$ & $1.20(0.67-2.15)$ & $2.19(0.82-5.86)$ \\
\hline \multicolumn{4}{|l|}{ Dairy products } \\
\hline Milk/cheese & $0.96(0.55-1.66)$ & $1.06(0.59-1.92)$ & $1.49(0.57-3.93)$ \\
\hline Sweetened dairy $\ddagger$ & $1.28(0.75-2.19)$ & $1.51(0.86-2.65)$ & $2.43(0.98-6.02)$ \\
\hline \multicolumn{4}{|l|}{ Junk foods } \\
\hline Snacks & $0.81(0.46-1.42)$ & $0.81(0.45-1.46)$ & $0.86(0.32-2.27)$ \\
\hline Sugar in tea§ & $0.76(0.43-1.34)$ & $0.69(0.38-1.25)$ & $0.34(0.14-0.84)^{\star}$ \\
\hline Table fats $\ddagger$ & $1.32(0.76-2.28)$ & $1.44(0.81-2.54)$ & $1.81(0.68-4.84)$ \\
\hline Sodas/coffee/tea etc. $\ddagger$ & $1.51(0.85-2.68)$ & $1.35(0.74-2.48)$ & $3.11(1.10-8.75)^{\star}$ \\
\hline Alcoholł & $1.30(0.72-2.34)$ & $1.41(0.75-2.64)$ & $3.44(1.14-10.40)^{*}$ \\
\hline
\end{tabular}

Model adjusted for age, energy intakes, other food group variables shown in table, any special diet, smoking history (never, past, current), education level (primary, secondary, college) and season (Jan-Mar, Apr-June, Jul-Aug, Sep-Dec).

*, $P<0.05$.

†Overweight/obesity defined as body mass index $\geq 25.0 \mathrm{~kg} \mathrm{~m}^{-2}$

‡ltems for which adjustment or restriction to plausible reporters yielded substantive changes and more credible associations.

$\S$ Sugar in tea is a substitute for sweetened condensed milk (sweet dairy group), which has a similar energy density but is also high in fat.

negative association between obesity and high intakes of green vegetables (spinach, cabbage and string beans: OR $0.37,95 \%$ CI $0.13-1.02$ ), but no association with orange/yellow (carrots, pumpkin, tomatoes: OR 0.95, 95\% CI 0.34-2.66) or high-fat 'vegetables' (ackee, avocado: OR $0.94,95 \%$ CI $0.38-2.34$ ). In men, a strong positive association with high-fat vegetables (OR 2.74, 95\% CI 1.02-7.39) appeared to underlie the positive association observed for all vegetables combined in the plausible subgroup. There was no association with green (OR 0.93, $95 \%$ CI $0.34-2.55$ ) or orange/yellow vegetables (OR 1.43, 95\% CI 0.53-3.92). Analysis of individual fruits did not provide insights on the positive association observed in the plausible reporter subgroup for men. Associations were positive for oranges and papaya, and negative for mangoes and bananas (not significant; not shown).

\section{Discussion}

Both under- and overreporting of energy intakes were highly prevalent in this middle-income developing country. Underreporting $(38.6 \%$ of women, $22.5 \%$ of men) was similar to levels reported in numerous studies in industrialised countries using FFQ data, in which prevalence generally ranged from 21 to $45 \%{ }^{10,13,25,28}$ Overreporting (23.7\% of men, $16.0 \%$ of women) was substantially higher than in a previous study that reported such data, where levels were $5-7 \%{ }^{10}$.

Little is known about implausible energy intake reporting in developing countries. Two previous studies in middle-income countries ${ }^{29}$ estimated underreporting of $43 \%$ (for FFQ data) in South Africa ${ }^{30}$ and 10\% (using a 24-hour recall) in Egyptian women ${ }^{12}$. Levels of $29.7 \%$, $16.2 \%$ and $17.6 \%$ during the first, second and third trimesters of pregnancy in Indonesia, a low-income country $^{31}$, and underreporting of $5 \%$ for Cameroon ${ }^{13}$, have been reported. An earlier descriptive analysis of these data reported high underreporting in Jamaica, although levels were lower than in the United Kingdom ${ }^{13}$. That analysis did not examine overreporting, or characteristics or food patterns of implausible reporters.

While similar to South Africa, underreporting in this sample of Jamaican adults was incongruous with the low levels observed in Egyptian women. Cultural differences may partly explain this disparity: the authors suggested that few Egyptian women may be self-conscious about diet or being overweight ${ }^{12}$. In contrast, young South Africans have a high prevalence of abnormal eating attitudes ${ }^{32}$. The discrepancy may also be partly attributable to methodological differences. There is no single approach for estimating underreporting; methods vary depending on dietary assessment techniques used, as well 
as availability of physical activity data. Since energy intakes in the Egyptian study were estimated from a single 24-hour recall, that study used a more conservative cut-off point $-0.92 \times$ BMR estimated using Schofield equations to define implausibly low intakes for a single day (given day-to-day variability). Interestingly, applying the cut-off point used in the Egyptian study to our FFQ data would have identified underreporting levels similar to those reported for Egypt: $5.41 \%$ in men and $9.65 \%$ in women.

Fully one-third of obese men and half of all obese women in this sample were underreporters. Thus, excluding underreporters would yield an analysis subgroup unlikely to be representative of obesity in the original random sample. The strong relationship between obesity and underreporting is consistent with other studies in both industrialised ${ }^{33}$ and developing countries ${ }^{12,31}$. However, it is not clear why some obese individuals underreport, while others do not. None the less, underreporting appears to have increased over time in developed countries ${ }^{34,35}$, while obesity levels, as well as the dissemination of dietary messages related to obesity, have been increasing. Rising obesity in developing countries may herald not only the need to examine how dietary patterns contribute to this epidemic ${ }^{36-38}$, but also shifts in attitudes that may make it more difficult to obtain valid self-reported dietary intakes.

In addition to helping to identify and target potential misreporters, adjusting for factors that characterise underreporters has been shown to decrease the association between BMI and underreporting ${ }^{6}$, and may help to reduce bias in analyses of diet and health outcomes. Besides obesity, however, less is known about other characteristics of underreporters. Yet a substantial proportion of normal-weight men (17.2\%) and women (25.3\%) were underreporters. Past underreporting has been shown to be a stronger predictor of current underreporting than BMI, suggesting that underreporters are a select group with a consistent tendency to underestimate intakes ${ }^{39}$. In this study, older age and dieting were significantly associated with underreporting even in normal-weight subjects (not shown). While associations with dieting have been fairly consistent $^{5,6,10,40,41}$, other characteristics may vary across populations. For example, significant positive associations with college education were reported in some ${ }^{10}$ but not all $^{40}$ studies. Several studies reported positive associations with smoking ${ }^{10}$; however, negative or no associations have also been reported ${ }^{40,42}$.

Few characteristics identified overreporters. Overweight and obesity were moderately but non-significantly associated with overreporting after adjustment. In men, past alcohol use and special diets were associated with overreporting after adjustment. Desire for weight gain and smoking were associated with overreporting in an earlier study $^{10}$. Further assessment of specific dieting practices associated with overreporting is needed.
No previous studies in developing countries have examined how food patterns of implausible and plausible reporters differ. Disparities across reporting groups were attenuated by using relative rather than absolute intakes, as observed in a few other studies ${ }^{41}$, suggesting that misreporters provided fairly consistent under- or overestimates of absolute intakes across numerous food groups $^{35,43}$. However, we also found that underreporters estimated a relatively low percentage of energy from 'unhealthy' foods such as snacks, and high intakes from healthy foods such as fruits. Several studies in industrialised countries also suggested that underreporters selectively underestimated high-fat or sugared foods compared with 'healthier' foods $9,11,33,35,42,44$. Selective underreporting has also been documented using biomarkers of intake ${ }^{2,34}$. Conversely, overreporters appeared to estimate relatively high intakes of high-fat and sugary foods ${ }^{10}$.

Perhaps most importantly, differential reporting in the implausible groups appeared to influence associations between food group intakes and obesity. Using absolute intakes, one previous study reported that including underreporters reversed the positive association between high-fat foods and obesity ${ }^{44}$. Like other studies, we observed that using energy-adjusted or relative intakes appeared substantially to reduce bias ${ }^{35,43}$. In addition, we found that adjusting for misreporting yielded even more credible associations.

An important limitation of this study is that data on physical activity levels, used to tailor estimated energy requirements based on individual lifestyles, were unavailable. To identify underreporters, we used a minimum physical activity level of $1.35 \times \mathrm{BMR}$, recommended as reasonable for all normal circumstances, and well below the level of $1.55 \times$ BMR corresponding to a sedentary lifestyle with light occupational work ${ }^{24}$. This method has been used previously ${ }^{10,25}$. The recommended equations for predicting $\mathrm{BMR}^{24}$ may overestimate BMR slightly in tropical countries ${ }^{45,46}$. However, these equations yielded estimates similar to measured BMR in Mexican women with comparable energy intakes (7.3 MJ urban, 9.24 MJ rural) and moderate physical activity levels $(1.65 \times$ BMR in urban and $1.90 \times$ BMR in rural women $)^{47}$. Furthermore, implausible reporting estimated as intakes within $\pm 30 \%$ of an independent prediction equation for total energy requirements ${ }^{27}$ was highly correlated (Spearman's $r=0.89)$ with estimates using this method.

Given the moderate response rate (60\%), we cannot exclude the possibility of bias. As we cannot ascertain how dietary attitudes or psychological characteristics of nonrespondents may differ from those of respondents, it is unclear whether and how non-response may have affected our findings. However, in our sample, estimated poverty (60\%) was somewhat higher than national estimates (40-60\% poverty in 1990-1998) ${ }^{48}$. As the poor were more likely to over- than underreport, our estimate of underreporting may be low. These data may also 
understate associations between underreporting and obesity, which were somewhat stronger in non-poor than poor adults (not shown).

The high prevalence of both under- and overreporting suggests the need to explore alternative techniques for collecting dietary data in developing countries in transition, as well as in industrialised countries ${ }^{49,50}$. More research is also needed to examine the prevalence and causes of overreporting in other developing countries. Calibration data, perhaps incorporating characteristics of misreporters, may also be used to improve intake estimates $^{28}$. However, in the absence of improved data, the use of relative intakes, along with adjustment for under- and overreporting, may help to reduce bias in associations between food group intakes and obesity or related health outcomes.

\section{Acknowledgements}

M Mendez received funding from NIH \#HL 45508, \#HL 53353, HD 30880 and HD 38700 during the preparation of this manuscript.

\section{References}

1 Heitmann BL, Lissner L. Dietary underreporting by obese individuals - is it specific or non-specific? British Medical Journal 1995; 311: 986-9.

2 Goris AH, Westerterp-Plantenga MS, Westerterp KR. Undereating and underrecording of habitual food intake in obese men: selective underreporting of fat intake. American Journal of Clinical Nutrition 2000; 71: 130-4.

3 Hirvonen $\mathrm{T}$, Mannisto $\mathrm{S}$, Roos $\mathrm{E}$, Pietinen $\mathrm{P}$. Increasing prevalence of underreporting does not necessarily distort dietary surveys. European Journal of Clinical Nutrition 1997; 51: 297-301.

4 Krebs-Smith SM, Graubard BI, Kahle LL, Subar AF, Cleveland LE, Ballard-Barbash R. Low energy reporters vs. others: a comparison of reported food intakes. European Journal of Clinical Nutrition 2000; 54: 281-7.

5 Lafay L, Basdevant A, Charles MA, Vray M, Balkau B, Borys $\mathrm{JM}$, et al. Determinants and nature of dietary underreporting in a free-living population: the Fleurbaix Laventie Ville Sante (FLVS) study. International Journal of Obesity and Related Metabolic Disorders 1997; 21: 567-73.

6 Braam LA, Ocke MC, Bueno-de-Mesquita HB, Seidell JC. Determinants of obesity-related underreporting of energy intake. American Journal of Epidemiology 1998; 147: 1081-6.

7 Hebert JR, Clemow L, Pbert L, Ockene IS, Ockene JK. Social desirability bias in dietary self-report may compromise the validity of dietary intake measures. International Journal of Epidemiology 1995; 24: 389-98.

8 Voss S, Kroke A, Klipstein-Grobusch K, Boeing H. Obesity as a major determinant of underreporting in a self-administered food frequency questionnaire: results from the EPICPotsdam Study. Zeitshrift fur Ernabrungswissenschaft 1997; 36: 229-36.

9 Johansson G, Wikman A, Ahren AM, Hallmans G, Johansson I. Underreporting of energy intake in repeated 24-hour recalls related to gender, age, weight status, day of interview, educational level, reported food intake, smoking habits and area of living. Public Health Nutrition 2001; 4: 919-27.
10 Johansson L, Solvoll K, Bjorneboe GE, Drevon CA. Underand overreporting of energy intake related to weight status and lifestyle in a nationwide sample. American Journal of Clinical Nutrition 1998; 68: 266-74.

11 Lafay L, Mennen L, Basdevant A, Charles MA, Borys JM, Eschwege E, et al. Does energy intake underreporting involve all kinds of food or only specific food items? Results from the Fleurbaix Laventie Ville Sante (FLVS) study. International Journal of Obesity and Related Metabolic Disorders 2000; 24: 1500-6.

12 Harrison GG, Galal OM, Ibrahim N, Khorshid A, Stormer A, Leslie J, et al. Underreporting of food intake by dietary recall is not universal: a comparison of data from Egyptian and American women. Journal of Nutrition 2000; 130: 2049-54.

13 Mennen LI, Jackson M, Cade J, Mbanya JC, Lafay L, Sharma S, et al. Underreporting of energy intake in four populations of African origin. International Journal of Obesity and Related Metabolic Disorders 2000; 24: 882-7.

14 Ataman SL, Cooper R, Rotimi C, McGee D, Osotimehin B, Kadiri $S$, et al. Standardization of blood pressure measurement in an international comparative study. Journal of Clinical Epidemiology 1996; 49: 869-77.

15 Cooper R, Rotimi C, Ataman S, McGee D, Osotimehin B, Kadiri $\mathrm{S}$, et al. The prevalence of hypertension in seven populations of West African origin. American Journal of Public Health 1997; 87: 160-8.

16 Sharma S, Cade J, Jackson M, Mbanya JC, Chungong S, Forrester $\mathrm{T}$, et al. Development of food frequency questionnaires in three population samples of African origin from Cameroon, Jamaica and Caribbean migrants to the UK. European Journal of Clinical Nutrition 1996; 50: 479-86.

17 Jackson M, Walker S, Cade J, Forrester T, Cruickshank JK, Wilks R. Reproducibility and validity of a quantitative foodfrequency questionnaire among Jamaicans of African origin. Public Health Nutrition 2001; 4: 971-80.

18 US Department of Agriculture, Agricultural Research Service. USDA Nutrient Database for Standard Reference, Release 15 [online]. Available at http://www.nal.usda.gov/fnic/foodcomp, 2002.

19 First DataBank, Inc. NutritionistPro. San Bruno, CA: The Hearst Corporation.

20 Caribbean Food and Nutrition Institute (CFNI). Food Composition Tables for Use in the English-Speaking Caribbean, 2nd ed. Kingston, Jamaica: CFNI Press, 1995.

21 Mennen LI, Jackson M, Sharma S, Mbanya JC, Cade J, Walker $\mathrm{S}$, et al. Habitual diet in four populations of African origin: a descriptive paper on nutrient intakes in rural and urban Cameroon, Jamaica and Caribbean migrants in Britain. Public Health Nutrition 2001; 4: 765-72.

22 Black AE. Critical evaluation of energy intake using the Goldberg cut-off for energy intake:basal metabolic rate. A practical guide to its calculation, use and limitations. International Journal of Obesity and Related Metabolic Disorders 2000; 24: 1119-30.

23 Schofield WN. Predicting basal metabolic rate, new standards and review of previous work. Human Nutrition. Clinical Nutrition 1985; 39(Suppl. 1): 5-41.

24 Goldberg GR, Black AE, Jebb SA, et al. Critical evaluation of energy intake data using fundamental principles of energy physiology: 1. Derivation of cut-off limits to identify underrecording. European Journal of Clinical Nutrition 1991; 45 : 569-81.

25 Samaras K, Kelly PJ, Campbell LV. Dietary underreporting is prevalent in middle-aged British women and is not related to adiposity (percentage body fat). International Journal of Obesity and Related Metabolic Disorders 1999; 23: 881-8.

26 Black AE, Coward WA, Cole TJ, Prentice AM. Human energy expenditure in affluent societies: an analysis of 574 doublylabelled water measurements. European Journal of Clinical Nutrition 1996; 50: 72-92. 
27 Vinken AG, Bathalon GP, Sawaya AL, Dallal GE, Tucker KL, Roberts SB. Equations for predicting the energy requirements of healthy adults aged 18-81 y. American Journal of Clinical Nutrition 1999; 69: 920-6.

28 Horner NK, Patterson RE, Neuhouser ML, Lampe JW, Beresford SA, Prentice RL. Participant characteristics associated with errors in self-reported energy intake from the Women's Health Initiative food-frequency questionnaire. American Journal of Clinical Nutrition 2002; 76: 766-73.

29 World Bank. World Development Indicators. New York: World Bank, 2002.

30 MacIntyre UE, Venter CS, Vorster HH. A culture-sensitive quantitative food frequency questionnaire used in an African population: 2 . Relative validation by 7 -day weighed records and biomarkers. Public Health Nutrition 2001; 4: 63-71.

31 Winkvist A, Persson V, Hartini TN. Underreporting of energy intake is less common among pregnant women in Indonesia. Public Health Nutrition 2002; 5: 523-9.

32 Szabo CP. Eating attitudes among black South Africans. American Journal of Psychiatry 1999; 156: 981-2.

33 Lissner L, Heitmann BL, Bengtsson C. Population studies of diet and obesity. British Journal of Nutrition 2000; 83(Suppl. 1): S21-4.

34 Heitmann BL, Lissner L, Osler M. Do we eat less fat, or just report so? International Journal of Obesity and Related Metabolic Disorders 2000; 24: 435-42.

35 Hirvonen $\mathrm{T}$, Mannisto $\mathrm{S}$, Roos $\mathrm{E}$, Pietinen $\mathrm{P}$. Increasing prevalence of underreporting does not necessarily distort dietary surveys. European Journal of Clinical Nutrition 1997; 51: 297-301.

36 Sichieri R. Dietary patterns and their associations with obesity in the Brazilian city of Rio de Janeiro. Obesity Research 2002; 10: 42-8.

37 Popkin BM. The nutrition transition and obesity in the developing world. Journal of Nutrition 2001; 131: 871S-3S.

38 Drewnowski A, Popkin BM. The nutrition transition: new trends in the global diet. Nutrition Reviews 1997; 55: 31-43.

39 Price GM, Paul AA, Cole TJ, Wadsworth ME. Characteristics of the low-energy reporters in a longitudinal national dietary survey. British Journal of Nutrition 1997; 77: 833-51.

40 Heitmann BL. The influence of fatness, weight change, slimming history and other lifestyle variables on diet reporting in Danish men and women aged 35-65 years.
International Journal of Obesity and Related Metabolic Disorders 1993; 17: 329-36.

41 Luhrmann PM, Herbert BM, Neuhauser-Berthold M. Underreporting of energy intake in an elderly German population. Nutrition 2001; 17: 912-6.

42 Pryer JA, Vrijheid M, Nichols R, Kiggins M, Elliott P. Who are the 'low energy reporters' in the dietary and nutritional survey of British adults? International Journal of Epidemiology 1997; 26: 146-54.

43 Voss S, Kroke A, Klipstein-Grobusch K, Boeing H. Is macronutrient composition of dietary intake data affected by underreporting? Results from the EPIC-Potsdam Study. European Prospective Investigation into Cancer and Nutrition. European Journal of Clinical Nutrition 1998; 52: 119-26.

44 Macdiarmid JI, Vail A, Cade JE, Blundell JE. The sugar-fat relationship revisited: differences in consumption between men and women of varying BMI. International Journal of Obesity and Related Metabolic Disorders 1998; 22: 1053-61.

45 Taaffe DR, Thompson J, Butterfield G, Marcus R. Accuracy of equations to predict basal metabolic rate in older women. Journal of the American Dietetic Association 1995; 95: 1387-92.

46 Henry CJ, Rees DG. New predictive equations for the estimation of basal metabolic rate in tropical peoples. European Journal of Clinical Nutrition 1991; 45: 177-85.

47 Sanchez-Castillo CP, Franklin M, McNeill G, de Lourdes Solano M, Bonner S, Lopez N, et al. Are the proposed limits of energy intake:basal metabolic rate and dietary nitrogen: urinary nitrogen ratios suitable for validation of food intake? British Journal of Nutrition 2001; 85: 725-31.

48 Private Investment Organization of Jamaica. Jamaica Survey of Living Conditions, 1998. Kingston, Jamaica: Private Investment Organization of Jamaica, 2002.

49 Calvert C, Cade J, Barrett JH, Woodhouse A. Using crosscheck questions to address the problem of mis-reporting of specific food groups on food frequency questionnaires. UKWCS Steering Group. United Kingdom Women's Cohort Study Steering Group. European Journal of Clinical Nutrition 1997; 51: 708-12.

50 Lindroos AK, Lissner L, Sjostrom L. Does degree of obesity influence the validity of reported energy and protein intake? Results from the SOS Dietary Questionnaire. Swedish Obese Subjects. European Journal of Clinical Nutrition 1999; 53: 375-8. 